Research report

\title{
Coffee for morning hunger pangs. An examination of coffee and caffeine on appetite, gastric emptying, and energy intake
}

\author{
Matthew M. Schubert ${ }^{\mathrm{a}, *}$, Gary Grant ${ }^{\mathrm{b}}$, Katy Horner ${ }^{\mathrm{c}, \mathrm{d}}$, Neil King ${ }^{\mathrm{c}}$, Michael Leveritt ${ }^{\mathrm{e}}$, \\ Surendran Sabapathy ${ }^{a}$, Ben Desbrow ${ }^{\text {a }}$ \\ a School of Allied Health Sciences, Griffith Health Institute, Griffith University, Gold Coast, Qld., Australia \\ b School of Pharmacy, Griffith University, Gold Coast, Qld., Australia \\ ' School of Exercise E' Nutrition Sciences and Institute of Health E' Biomedical Innovation, Queensland University of Technology, Brisbane, Qld., Australia \\ ${ }^{\mathrm{d}}$ Division of Weight Management E' Wellness, Children's Hospital of Pittsburgh of UPMC, University of Pittsburgh School of Medicine, Pittsburgh, PA, USA \\ e School of Human Movement Studies, University of Queensland, St. Lucia, Qld., Australia
}

\section{A R T I C L E I N F O}

\section{Article history:}

Received 29 May 2014

Received in revised form 5 September 2014

Accepted 7 September 2014

Available online

\section{Keywords:}

Appetite

Caffeine

Coffee

Energy intake

Gastric emptying

\begin{abstract}
A B S T R A C T
Introduction: Coffee is one of the most widely consumed beverages in the world and has a number of potential health benefits. Coffee may influence energy expenditure and energy intake, which in turn may affect body weight. However, the influence of coffee and its constituents - particularly caffeine and chlorogenic acids - on appetite remains largely unexplored. Purpose: The objective of this study was to examine the impact of coffee consumption (with and without caffeine) on appetite sensations, energy intake, gastric emptying, and plasma glucose between breakfast and lunch meals. Methods: This study utilised a doubleblind, randomised crossover design. Participants $(n=12,9$ women; Mean \pm SD age and BMI: $26.3 \pm 6.3$ y and $22.7 \pm 2.2 \mathrm{~kg}^{\bullet} \mathrm{m}^{-2}$ ) completed 4 trials: placebo (PLA), decaffeinated coffee (DECAF), caffeine (CAF), and caffeine with decaffeinated coffee (COF). Participants were given a standardised breakfast labelled with ${ }^{13} \mathrm{C}$-octanoic acid and $225 \mathrm{~mL}$ of treatment beverage and a capsule containing either caffeine or placebo. Two hours later, another $225 \mathrm{~mL}$ of the treatment beverage and capsule was administered. Four and a half hours after breakfast, participants were given access to an ad libitum meal for determination of energy intake. Between meals, participants provided exhaled breath samples for determination of gastric emptying every $15 \mathrm{~min}$; venous blood (for examination of glucose) and appetite sensations (via visual analogue scales) were collected every hour. Results: Energy intake was not significantly different between the trials (Means \pm SD, $p>0.05$; Placebo: $2118 \pm 663$ kJ; Decaf: $2128 \pm 739$ kJ; Caffeine: $2287 \pm 649$ kJ; Coffee: $2016 \pm 750 \mathrm{~kJ})$; Other than main effects of time $(p<0.05)$, no significant differences were detected for appetite sensations or plasma glucose between treatments $(p>0.05)$. Gastric emptying was not significantly different across trials $(p>0.05)$. Conclusions: Utilising an ecologically valid design, no significant effects of decaffeinated coffee, caffeine or their combination were detected on gastric emptying, appetite sensations, glucose, and energy intake. However, the consumption of caffeine and/or coffee for regulation of energy balance over longer periods of time warrant further investigation.
\end{abstract}

(C) 2014 Elsevier Ltd. All rights reserved.

\section{Introduction}

Energy balance is an important concept in weight and obesity management, as understanding and manipulating energy balance can lead to changes in body composition and/or body weight. Caffeine is the most widely consumed psychoactive substance in the

Acknowledgements: The authors thank Susan Hall for her assistance with the HPLC analysis of CGAs, Andrew Bulmer for his assistance with the glucose analysis, and Connie Wishart for her assistance with the gastric emptying analysis.

* Corresponding author.

E-mail address: m.schubert@griffith.edu.au (M.M. Schubert). world, with a recent study reporting $85 \%$ of a sample population $(\sim 38,000)$ consumed one or more caffeine-containing beverages a day (Mitchell, Knight, Hockenberry, Teplansky, \& Hartman, 2013). Thus, it is important to examine the influence of caffeine on determinants of energy balance, as coffee and caffeine consumption have been found to have mild (but significant) associations with attenuated weight gain. Greenberg and colleagues reported that as caffeinated and decaffeinated coffee consumption increases, the likelihood of gaining weight decreases (Greenberg, Axen, Schnoll, \& Boozer, 2005). This is supported by evidence from large cohort studies that reported increases in daily caffeine consumption led to a lower weight gain in older adults (Lopez-Garcia et al., 2006) and that increments of 1 cup of coffee per day were associated with $0.14 \mathrm{~kg}$ less weight gain per four-year period (Pan, et al., 2013). 
However, the mechanisms of the potential weight-reducing effects of coffee and caffeine are not clearly known, although several have been postulated including alterations in energy expenditure and energy intake. There is strong evidence that caffeine can lead to moderate increases in resting energy expenditure ( $5 \%$ over $24 \mathrm{~h}$ ) (Hursel et al., 2011). The effects on appetite and energy intake are more variable, with some studies reporting reductions in energy intake in response to caffeine (Tremblay, Masson, Leduc, Houde, \& Despres, 1988), while others do not report changes whether caffeine (Judice et al., 2013a,b) or coffee (Gavrieli et al., 2011, 2013) are ingested. Coffee's effects on gastrointestinal function have also been examined, as alterations in gut hormones or gastric emptying (GE) could influence appetite and energy intake (Horner, Byrne, Cleghorn, Naslund, \& King, 2011). As with appetite and energy intake, results for GE responses to coffee ingestion remain equivocal, though responses to caffeine have not been separately examined (Akimoto et al., 2009; Franke, Harder, Orth, Zitzmann, \& Singer, 2008). Finally, coffee and caffeine potentiate postprandial blood glucose responses (Gavrieli, Fragopoulou, Mantzoros, \& Yannakoulia, 2013;), and the postprandial glucose response may be linked with subsequent energy intake (Flint et al., 2006).

The literature to date has some methodological issues that may limit applications to larger populations; namely the use of one bolus dose of coffee (Gavrieli et al., 2011, 2013; Greenberg \& Geliebter, 2012) and GE assessment of coffee as a complete beverage (Akimoto et al., 2009; Franke et al., 2008). A recent study that examined the beverage consumption patterns of adults in the UK reported that consumption of hot beverages (i.e. coffee, tea, cocoa, etc.) peaks in the morning (0600-0800) with a second, smaller peak late morning (1000-1200), in both men and women (Gibson \& Shirreffs, 2013). Thus, individuals may consume multiple beverages between meals, and the influence of this multiple dosing pattern on appetite and energy intake remains to be investigated.

Clearly, additional research is required to fully understand the influence of caffeine and coffee intake on psychological and physiological mediators of food consumption. Therefore, the aim of this study was to explore various potential mechanisms of how a split dose of caffeine and coffee may affect appetite sensations, energy intake, and gastric emptying. It was hypothesized that caffeine would independently, and in combination with coffee, acutely decrease hunger, and attenuate gastric emptying, without alterations in energy intake.

\section{Methods}

This study utilised a randomised, double-blind, placebo-controlled crossover design. The study was approved (GU HREC PBH/18/12) by the institutional ethics committee and conformed to the Declaration of Helsinki.

\section{Treatments}

Four distinct treatments were utilised in this study (Table 1). The control condition consisted of placebo capsules (Metamucil ${ }^{\circledR}$ ) and water. The decaf condition was placebo capsules and decaffeinated coffee (Nescafe ${ }^{\circledR}$ Instant Decaf). The caffeine condition provided pure, encapsulated caffeine (PCCA, Matraville, NSW, Australia) with

Table 1

Matrix of treatment conditions.

\begin{tabular}{lll}
\hline Condition & Beverage & Capsules \\
\hline Placebo (PLA) & Water & Placebo (Metamucil®) \\
Caffeine (CAF) & Water & Caffeine \\
Coffee + CAF (COF) & Decaffeinated coffee & Caffeine \\
Decaffeinated coffee (DECAF) & Decaffeinated coffee & Placebo (Metamucil®) \\
\hline
\end{tabular}

water, and the coffee condition involved participants consuming caffeine capsules and decaffeinated coffee. All caffeine doses provided a total dose of $4 \mathrm{mg} \cdot \mathrm{kg}^{-1} \mathrm{BM}$ in two equivalent doses. This dose was chosen because it was between the doses used in prior studies (Gavrieli et al., 2011; Greenberg \& Geliebter, 2012) and similar to the estimated daily consumption of our participants. Capsules were used to mask the detection of the presence of caffeine dissolved in water or subtle differences between regular and decaffeinated coffee. The coffee was provided in two 5-g boluses dissolved in $225 \mathrm{~mL}$ of water and served at $\sim 50{ }^{\circ} \mathrm{C}$. Equal volumes of cool tap water $(\sim 15$ ${ }^{\circ} \mathrm{C}$ ) were provided in the non-coffee conditions (beverage temperature has been reported to have no influence on GI function (McArthur \& Feldman, 1989)). We utilised Metamucil as our placebo as it has been previously used by our group (Desbrow, Barrett, Minahan, Grant, \& Leveritt, 2009) due to its similar texture to anhydrous caffeine. While psyllium (Metamucil ${ }^{\circledR}$ ) has been shown to influence gastric emptying, appetite, and energy intake, this requires significant amounts (10-20 g) (Bergmann et al., 1992; Turnbull \& Thomas, 1995). The $\sim 250 \mathrm{mg}$ that participants received in the present study would have likely been insufficient to cause any confounding effects.

We chose to utilise two bolus doses of coffee to mimic natural consumption, i.e. a beverage with breakfast followed by a second ingested mid-morning. Coffee consumption usually peaks in the morning (0600-0800) with a second, smaller peak late morning (1000-1200), during the week in both men and women (Gibson \& Shirreffs, 2013). Time-to-peak caffeine concentration was also considered during study design; though it is highly variable depending on the individual (Skinner, Jenkins, Taaffe, Leveritt, \& Coombes, 2013b), caffeine levels appear to peak around $2-2.5 \mathrm{~h}$ post-ingestion. Thus, the timing of the coffee/caffeine doses were designed to maintain elevated plasma caffeine levels during the trial.

Metabolic activity of the capsules was not verified in this study; however, the same capsules, prepared in the exact same manner and with a similar dosing regimen $\left(2 \times 3 \mathrm{mg} \cdot \mathrm{kg}^{-1} \mathrm{BM}\right)$, were recently used by us in a similarly designed study (Schubert et al., 2014). In that study, samples for plasma caffeine were determined at baseline $(-30),+15$ (45 min post), +60 (90 min post), 180 (30 min post2nd dose), and $240 \mathrm{~min}$ (90 min post-2nd dose). Caffeine levels exhibited a 'double-peak' of $\sim 20 \mu \mathrm{M} \bullet \mathrm{L}^{-1}$ at $60 \mathrm{~min}$ and $\sim 32 \mu \mathrm{M} \bullet \mathrm{L}^{-1}$ at $240 \mathrm{~min}$ (exercise was conducted from 60-120 min and a 2 nd caffeine dose ingested at $150 \mathrm{~min}$ ) (Schubert et al., 2014).

Because it was not possible to blind participants to coffee versus water in the present design, they were aware of when they were receiving coffee - but they and the investigators remained blind to caffeine administration. As the true purpose of this study was to assess energy intake as a primary outcome, and appetite perceptions as a secondary outcome, participants were blinded by informing them that the aim of the study was to examine how encapsulated caffeine and caffeine in coffee influenced gastric emptying and markers of metabolism and oxidative stress. On completion of all trials participants were debriefed and asked to try and identify the order of their treatments and the associated certainty with their choices ("no idea", "somewhat certain", "reasonably certain", and "absolutely certain"). Participants were randomised according to a Latin Squares design and an individual not associated with the research allocated caffeine and placebo capsules into envelopes containing only a trial number and participant identification.

\section{Participants, familiarisation and experimental controls}

Participants provided written informed consent and completed questionnaires to assess health, physical activity habits, and dietary habits (Stunkard \& Messick, 1985) before enrolment. The latter was used to ensure the exclusion of individuals with atypical or abnormal eating patterns which could have potentially 
confounded the study outcomes. Participants also completed a caffeine-consumption questionnaire to quantify daily caffeine consumption (Desbrow, 2011). The inclusion criteria for the recruitment of participants were as follows: non-smoking, non-obese men and pre-menopausal women $\left(\mathrm{BMI}<30 \mathrm{~kg} \bullet \mathrm{m}^{-2}\right.$ ) between 18 and 45 years of age; not taking any medicine known to influence lipid, carbohydrate, or caffeine metabolism; not dieting and did not have any extreme dietary behaviours (Three Factor Eating Questionnaire (Stunkard \& Messick, 1985): cut-off points $<9$ for inhibition, $<12$ for restraint, and $<8$ for hunger); weight stable in the previous 3 months ( $\pm 5 \%$ by self-report); no history of any cardiovascular or metabolic diseases; no food allergies or intolerances; and no history of gastrointestinal disorders.

Prior to commencing the study, all participants attended a familiarisation session where body composition and anthropometry were assessed using established criteria (Heyward, 2006). Participants were also familiarised with the computer questionnaires to be completed during each trial.

A standard evening meal was provided for each participant for each trial (Lean Cuisine ${ }^{\circledR}$, Simplot Australia, Australia; Woolworth's Garlic Bread, Woolworth Supermarkets, Australia). The dinner meal, comprising $3073 \pm 506 \mathrm{~kJ}$ ( $109 \pm 20 \mathrm{~g}$ carbohydrate, $25 \pm 4$ g protein, $21 \pm 4 \mathrm{~g}$ fat), was equivalent to $\sim 30 \%$ of each individual's daily energy needs, estimated using the Harris-Benedict equation, with adjustments for activity levels and the thermic effect of food (Harris \& Benedict, 1918; Westerterp, Donkers, Fredrix, \& Boekhoudt, 1995). Participants were also required to standardise their food intake in the $24 \mathrm{~h}$ prior to each trial using a comprehensive food record of all items consumed during this period. The records were photocopied and subsequently returned to the participants so they could replicate their intake for the remaining trials. Any of the dinner not eaten was returned the next day. Also for $24 \mathrm{~h}$ prior to each trial, participants were instructed to abstain from strenuous exercise, alcohol, and foods naturally enriched in ${ }^{13} \mathrm{C}$ (corn and corn-based products, kiwi, pineapple, cane sugar). For $36 \mathrm{~h}$ before each trial, participants were asked to refrain from consuming anything containing caffeine or known to influence caffeine metabolism (i.e. cruciferous vegetables, charcoal-broiled beef, aspirin, and cimetidine) (Bouchard, Weber, \& Geiger, 2002). Participants were given a list of items to avoid and also had blood taken for determination of plasma caffeine concentrations at the beginning of each trial.

Women were tested during the follicular phase of the menstrual cycle, as determined by self-report. Because a 3-4 day washout period was required between conditions, only two conditions were completed during each menstrual cycle, with the remaining two conditions completed on identical days of the following month's menstrual cycle; women taking oral contraceptives $(n=5)$ were tested at equivalent time points of their pill pack. Thus, in women, testing conditions were completed over the course of two menstrual cycles to ensure that testing outcomes were unaffected by changes in sex hormones, energy expenditure, substrate oxidation, and energy intake that may occur during different phases of the menstrual cycle (McNeil \& Doucet, 2012).

\section{Experimental trials}

\section{Overview}

An overview of the experimental trials is shown in Fig. 1. Briefly, participants arrived in the morning between 0600 and 0900 after an overnight fast, consuming nothing other than water after 2200. Participants were then seated in a semi-supine position for $10 \mathrm{~min}$ while providing perceived levels of appetite and food (FPQ) preferences using computer-based visual analogue scales (VAS). A cannula was subsequently inserted into an antecubital vein and a baseline blood sample was taken. After the initial blood sample, participants were provided with their first treatment and a ${ }^{13} \mathrm{C}$ labelled breakfast and asked to consume it within $15 \mathrm{~min}$. After ingesting the first treatment bolus with breakfast, the FPQ was immediately completed followed by appetite ratings and blood sampling, which were subsequently obtained every 60 minutes throughout the trial until $240 \mathrm{~min}$. Breath samples, for ${ }^{13} \mathrm{C}$-isotopic analysis, were obtained 25 and 10 minutes before breakfast, immediately after, and every 15 min thereafter until $270 \mathrm{~min}$. The second treatment bolus was administered at $120 \mathrm{~min}$. Water was provided in two $125 \mathrm{~mL}$ boluses at $150 \mathrm{~min}$ and $210 \mathrm{~min}$. At $270 \mathrm{~min}$, participants again completed the FPQ and were given access to an ad libitum homogenous pasta meal and instructed to eat, over a period of 30 minutes, until satisfied. Upon completion of the meal,

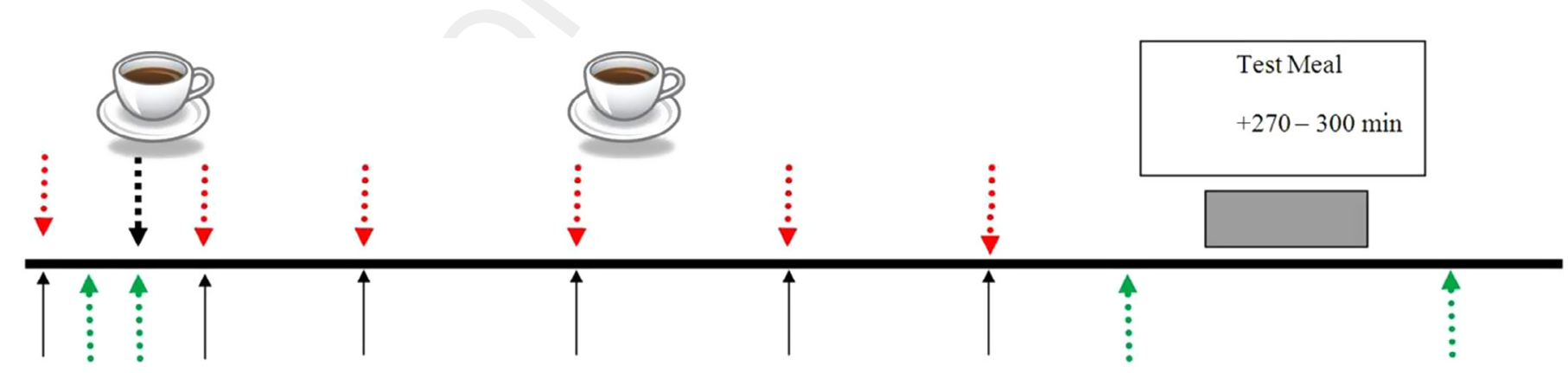

\begin{tabular}{|l|l|l|l|l|l|l|l|}
\hline-30 & 0 & +60 & +120 & +180 & +240 & +270 & +300 \\
\hline
\end{tabular}

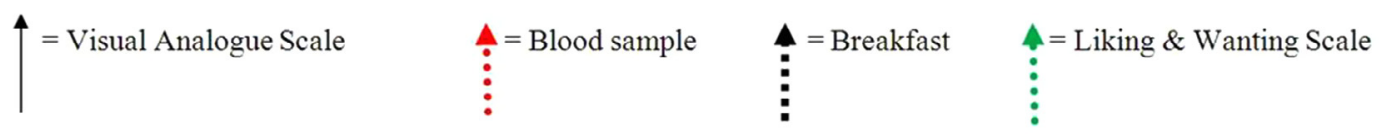

\footnotetext{
${ }^{* 13} \mathrm{C}$ breath samples were taken at arrival $(-30),-15$, and every 15 min from post-breakfast to $4.5 \mathrm{hr}(270 \mathrm{~min})$
}

Fig. 1. Schematic of experimental trials. 
participants completed a final FPQ. Throughout the trials, participants were permitted to perform sedentary activities (reading, studying, using a computer, watching movies) and use the toilet as needed. Room temperature and humidity were controlled throughout all trials $\left(22 \pm 3{ }^{\circ} \mathrm{C} ; 54 \pm 5 \%\right)$.

\section{Assessment of appetite sensations}

Hunger, fullness, satisfaction, prospective food consumption, thirst, desire to eat something salty, and desire to eat something sweet were assessed periodically using previously validated computerised visual analogue scales (Adaptive VAS, San Antonio, USA) (Flint, Raben, Blundell, \& Astrup, 2000).

\section{Assessment of gastric emptying}

Gastric emptying was assessed by the ${ }^{13} \mathrm{C}$ octanoic acid breath test as previously described (Ghoos et al., 1993; Horner, Byrne, Cleghorn, \& King, 2013). A standardised breakfast (pancakes, butter, and jam, providing $1676 \mathrm{~kJ}, 48 \mathrm{~g}$ CHO, $17 \mathrm{~g}$ FAT, $15 \mathrm{~g}$ PRO) was provided containing $100 \mathrm{mg}$ of ${ }^{13} \mathrm{C}$-labelled octanoic acid (Cambridge Isotope Laboratories, USA). Breath samples were collected 25 and $10 \mathrm{~min}$ before the test meal was administered and then for every $15 \mathrm{~min}$ from immediately post-meal for 4.5 hours (270 min). Breath samples were collected into $10 \mathrm{~mL}$ test tubes (Exetainer, Labco Limited, UK) as has been previously described, immediately capped, and stored for later analysis (Ghoos et al., 1993; Hellmig et al., 2006; Horner et al., 2013; Jackson, Bluck, \& Coward, 2004). The ${ }^{13} \mathrm{C}-$ isotopic enrichment of the breath samples was measured using a mass spectrometer (Hydra 20-20; Europa Scientific, UK) against a calibrated reference gas $\left(5 \% \mathrm{CO}_{2}, 75 \% \mathrm{~N}_{2}, 20 \% \mathrm{O}_{2}\right)$ and changes in the ${ }^{13} \mathrm{C} /{ }^{12} \mathrm{C}$ ratio from initial values and cumulative doses were measured (Horner et al., 2013). Data were fitted to established gastric emptying regression models for the determination of lag time $\left(t_{\mathrm{lag}}\right.$, the time taken to reach maximal ${ }^{13} \mathrm{CO}_{2}$ excretion) and half excretion time $\left(t_{1 / 2}\right.$, time taken for half of the ${ }^{13} \mathrm{C}$ dose to be excreted in the breath) (Ghoos et al., 1993). In addition, the parameters of latency time $\left(t_{\text {lat }}\right)$ and ascension time $\left(t_{\text {asc }}\right)$ were calculated according to Schommartz and colleagues (Schommartz, Ziegler, \& Schadewaldt, 1998). Latency time refers to the initial delay in the ${ }^{13} \mathrm{C}$ excretion curve, which is indicative of initial emptying, while ascension time refers to the time course between $t_{\mathrm{lag}}$ and $t_{1 / 2}$ when high rates of ${ }^{13} \mathrm{C}$ excretion occur (Horner et al., 2013; Schommartz et al., 1998).

\section{Assessment of ad libitum energy intake}

Participants were given access to an ad libitum homogenous pasta meal (Beef lasagne, Sara Lee ${ }^{\circledR}$, Australia) for a period of $30 \mathrm{~min}$ and instructed to eat until satisfied. Food was provided in excess of expected consumption ( $~ 800 \mathrm{~g} ; 5000 \mathrm{~kJ})$. Calculations of total energy intake involved weighing remaining food after the participant had left the laboratory and subtracting these values from initial weight values. Energy intake and macronutrient composition were determined using the manufacturers' published nutritional values. The test meal procedure has been verified as a reproducible method, with a coefficient of variation (CV) of $9 \%$ when diet is standardised beforehand (Gregersen et al., 2008). The homogenous meal was chosen over a buffet-type meal for logistical reasons and to avoid the "banquet effect". Participants consumed their meals in thermoneutral conditions in the lab singly or in pairs with the investigator in a separate room.

\section{Blood sample collection and analysis}

At baseline, $3 \mathrm{~mL}$ of venous blood was collected into lithium heparin tubes (BD Vacutainer, North Ryde, Australia) for determination of plasma caffeine, while $1 \mathrm{~mL}$ of blood was collected into fluoride oxalate tubes (BD Vacutainer, North Ryde, Australia) for glucose analysis. Blood samples at subsequent time points were utilised for measurement of glucose only. All blood samples were centrifuged at $3000 \mathrm{rpm}$ for $15 \mathrm{~min}$ at $4{ }^{\circ} \mathrm{C}$ with the plasma aliquotted and stored at $-80^{\circ} \mathrm{C}$ for subsequent analysis.

Glucose was assayed on an automated Cobas Integra diagnostic system (Roche Diagnostics, Switzerland) using a hexokinase reagent kit (Glucose HK Gen.3, Roche Diagnostics, Switzerland).

Baseline plasma caffeine was analysed using an automated high performance liquid chromatography (HPLC) system, as previously described (Desbrow et al., 2009). The identity and purity of caffeine peaks were achieved by spectral purity analysis, and comparison with pure caffeine verification samples.

All assays for each participant were performed in duplicate, with intrassay coefficients of variation of $0.8 \%$ for glucose and $1.7 \%$ for plasma caffeine.

\section{Assessment of coffee beverages}

Quantity of caffeine in the coffee beverages was determined using HPLC as described above for analysis of plasma caffeine. Coffee beverages were prepared by adding $10 \mathrm{~g}$ of coffee grounds to $450 \mathrm{~mL}$ of boiling water and mixed vigorously. Ten $1.5 \mathrm{~mL}$ aliquots were then obtained and immediately analysed in triplicate. For CGAs, total CGA contents were determined as per the methods of Narita and Inouye, with minor modifications (Narita \& Inouye, 2013).

\section{Statistical analysis}

According to previous research (Gregersen et al., 2008), a sample size of 17 participants would be necessary to detect a $500 \mathrm{~kJ}$ difference in energy intake, in a paired design with prior dietary standardisation, at a power level of $80 \%$. Although 18 participants (15 women, 3 men) were initially recruited and screened, 12 (9 women, 3 men) completed the study. Six women withdrew at various phases of testing; the primary reasons for drop-out were illness, work/family commitments, and unwillingness to comply with dietary standardisation.

Statistical analysis was conducted using SPSS version 21 (SPSS Inc., Chicago, IL). All variables were examined for normality using the Shapiro-Wilk test. Analyses included standard descriptive measures and 2-way (Treatment * Time) repeated-measures ANOVA for time-related variables (appetite sensations, food preference, and biochemical data). If a significant $F$ ratio was detected, the Bonferroni post hoc correction for multiple comparisons was used. Area under the concentration-time curve (AUC) calculations were performed using the trapezoidal method for hormonal and VAS measures. AUC measures, gastric emptying parameters, energy intake and meal weight were examined using a one-way repeated-measures ANOVA with the Bonferroni correction for multiple comparisons utilised if a significant $F$ ratio was detected. The Pearson product moment correlation coefficient was used to examine relationships between energy intake and other variables. No corrections for multiple correlations were applied. Data in text and tables are presented as means \pm SD whilst figures are presented as means \pm SEM for clarity. Statistical significance was accepted at $p<0.05$.

\section{Results}

Twelve participants completed the study (9 women, 3 men). The descriptive characteristics of the participants who completed all trials are summarised in Table 2. Analysis of baseline blood samples for plasma caffeine and glucose indicated no significant differences between trials, confirming compliance with caffeine abstinence (defined as plasma caffeine levels of $<1 \mu \mathrm{M} \bullet \mathrm{L}^{-1}$ ) (Table 3 ).

While 5 participants correctly identified their order of treatments, all participants $(n=12)$ rated their certainty of administered treatments below "reasonably certain" levels. No participants 
Table 2

Characteristics of participants $(\mathrm{n}=12)$.

\begin{tabular}{|c|c|}
\hline Measure & Mean \pm SD \\
\hline Age (years) & $26.3 \pm 6.3$ \\
\hline Height (cm) & $169.6 \pm 6.4$ \\
\hline Mass (kg) & $65.4 \pm 8.3$ \\
\hline $\mathrm{BMI}\left(\mathrm{kg} \bullet \mathrm{m}^{-2}\right)$ & $22.7 \pm 2.2$ \\
\hline$\%$ Body fat & $16.5 \pm 4.2$ \\
\hline Caffeine consumption $\left(\mathrm{mg}^{\bullet} \mathrm{d}^{-1}\right)^{\mathrm{a}}$ & $240(22-742)$ \\
\hline Dietary restraint $(<12)$ & $8.0 \pm 2.4$ \\
\hline Dietary inhibition $(<9)$ & $4.25 \pm 2.4$ \\
\hline Hunger $(<8)$ & $4.75 \pm 2.6$ \\
\hline Caffeine dose $(\mathrm{mg})^{\mathrm{b}}$ & $262 \pm 33$ \\
\hline Coffee-caffeine dose $(\mathrm{mg})^{c}$ & $278 \pm 32$ \\
\hline \multicolumn{2}{|l|}{ a Mean plus range. } \\
\hline \multicolumn{2}{|l|}{ b $4 \mathrm{mg} \bullet \mathrm{kg}^{-1} \mathrm{BM}$} \\
\hline c $4 \mathrm{mg} \bullet \mathrm{kg}^{-1} \mathrm{BM}$ plus trace amou & \\
\hline
\end{tabular}

indicated the primary aim of the study was to assess ad libitum energy intake.

No effect of trial order was found for any variable examined; nor was energy intake different in the $24 \mathrm{~h}$ preceding each trial $(p>0.5$ for all). Additionally, removal of the 3 men from the analyses did not cause any alterations in results; therefore, their results have been retained.

\section{Characteristics of coffee beverages}

HPLC analysis of the coffee revealed small amounts of caffeine, equal to $14.8 \pm 3.3 \mathrm{mg}$ per $450 \mathrm{~mL}$ serve; this is comparable to that reported previously for the same brand of coffee (Hodgson, Randell, \& Jeukendrup, 2013). Total CGA content was also similar, equal to $248.9 \pm 11.3 \mathrm{mg}\left(1.56 \mathrm{mmol} \bullet \mathrm{L}^{-1}\right)$ per serve (Hodgson et al., 2013).

\section{Energy intake}

Mean results for ad libitum food ( $\mathrm{g}$ ) and energy intake $(\mathrm{kJ})$ are displayed in Table 3. Individual results for energy intake are displayed in Fig. 2. No differences between treatments for energy intake were detected $\left(F_{3,33}=2.00 ; p=0.133\right)$. Weight of food consumed was significantly different between trials $\left(F_{3,33}=3.69 ; p=0.021\right)$, with participants consuming $51 \mathrm{~g}(13.2 \%)$ less during the COF compared to the CAF trial $(p=0.007)$.
Appetite perceptions and food preference

Results for hunger, satisfaction, fullness, and prospective food consumption are shown in Fig. 3A-D. There was a main effect of time for all appetite sensations $(p<0.001)$ but no effect of treatment $(p>0.3$ for all) or a time-by-treatment interaction ( $p>0.4$ for all).

There were no differences between treatments in AUC for hunger $\left(F_{3,33}=1.379 ; p=0.266\right)$. Satisfaction $\left(F_{3,33}=3.574 ; p=0.024\right)$, fullness $\left(F_{3,33}=4.006 ; p=0.015\right)$, and prospective food consumption $\left(F_{3,33}=2.893 ; p=0.05\right)$ revealed main effects of trial, but none of the post-hoc comparisons were significant ( $p>0.05$ for all) (Table 3 ).

Post-meal palatability ratings for the ad libitum lunch were not significantly different between the trials (CON: $75.3 \pm 7.7$, DECAF: $76.4 \pm 9.0$, CAF: $76.2 \pm 5.4$, COF: $78.9 \pm 10.6 ; p=0.513$ ), indicating the participants found the meal acceptable and that this was consistent across trials.

\section{Gastric emptying}

Complete gastric emptying data were obtained from 9 participants for all four trials. The reasons for the three missing data sets were that two necessitated exclusion as they did not meet the acceptance criteria for the regression models $\left(r^{2} \geq 0.9\right)$, whilst the third was missing a number of data points that precluded accurate analysis. Results for gastric emptying parameters are shown in Table 3. There was a main effect of trial for latency time $\left(F_{3,24}=3.871\right.$; $p=0.022)$ and a trend for an effect for lag time $\left(F_{3,24}=2.955\right.$; $p=0.053$ ), but post-hoc comparisons were not significantly different $(p>0.05)$. Half-time $\left(F_{3,24}=1.976 ; p=0.145\right)$ and ascension time $\left(F_{3,24}=1.527 ; p=0.233\right)$ were not significantly different. These results indicate that ingestion of caffeine, coffee, or decaffeinated coffee did not influence gastric emptying when compared to placebo. However, there was significant variability in GE responses during the coffee trial as illustrated by the large standard deviation.

\section{Glucose}

Due to problems with cannulation of two participants, glucose is reported for 10 participants. Baseline values for plasma glucose and glucose AUC are summarised in Table 3.

There was a main effect of time for glucose $(p<0.001)$ but no effect of treatment ( $p=0.84$ ) or a time-by-treatment interaction $(p=0.77)$. Glucose levels peaked after breakfast, reached their nadir one hour later, and returned to near baseline levels by $2 \mathrm{~h}$, where

Table 3

Results for energy intake, meal weight, appetite sensation area under the concentration-time curves (AUCs), and gastric emptying parameters.

\begin{tabular}{|c|c|c|c|c|c|}
\hline Variable & Placebo & Decaf & Caffeine & Coffee & P-value \\
\hline Baseline caffeine $\left(\mu \mathrm{M} \bullet \mathrm{L}^{-1}\right)^{\mathrm{a}}$ & $0.34 \pm 0.46$ & $0.15 \pm 0.19$ & $0.22 \pm 0.21$ & $0.41 \pm 0.51$ & 0.133 \\
\hline Baseline glucose $\left(\mathrm{mmol} \cdot \mathrm{L}^{-1}\right)^{\mathrm{a}}$ & $5.08 \pm 0.3$ & $5.09 \pm 0.48$ & $4.85 \pm 0.61$ & $4.75 \pm 0.84$ & 0.519 \\
\hline Energy Intake (kJ) & $2118 \pm 663$ & $2128 \pm 739$ & $2287 \pm 648$ & $2016 \pm 750$ & 0.133 \\
\hline Weight of meal consumed $(\mathrm{g})$ & $355 \pm 77$ & $356 \pm 86$ & $385 \pm 64$ & $334 \pm 94^{b}$ & 0.021 \\
\hline Hunger AUC $\left(\mathrm{mm} \bullet 4.5 \mathrm{~h}^{-1}\right)$ & $195 \pm 92$ & $218 \pm 81$ & $212 \pm 89$ & $189 \pm 70$ & 0.266 \\
\hline Satisfaction AUC $\left(\mathrm{mm} \bullet 4.5 \mathrm{~h}^{-1}\right)$ & $212 \pm 85$ & $233 \pm 76$ & $210 \pm 85$ & $237 \pm 68$ & 0.024 \\
\hline Fullness AUC $\left(\mathrm{mm} \bullet 4.5 \mathrm{~h}^{-1}\right)$ & $200 \pm 86$ & $229 \pm 82$ & $203 \pm 85$ & $234 \pm 69$ & 0.015 \\
\hline Prospective food consumption AUC $\left(\mathrm{mm} \bullet 4.5 \mathrm{~h}^{-1}\right)$ & $238 \pm 93$ & $253 \pm 78$ & $229 \pm 88$ & $212 \pm 77$ & 0.05 \\
\hline Glucose AUC & $22.08 \pm 1.76$ & $22.25 \pm 3.18$ & $21.55 \pm 2.67$ & $21.40 \pm 2.84$ & 0.594 \\
\hline \multicolumn{6}{|l|}{$\left(\mathrm{mmol} \cdot \mathrm{L}^{-1} / 4.5 \mathrm{~h}^{-1}\right)(\mathrm{n}=10)$} \\
\hline$t_{\text {lat }}(\min )(\mathrm{n}=9)$ & $39 \pm 14$ & $50 \pm 27$ & $34 \pm 14$ & $36 \pm 18$ & 0.022 \\
\hline$t_{\operatorname{lag}}(\min )(\mathrm{n}=9)$ & $115 \pm 29$ & $120 \pm 29$ & $98 \pm 23$ & $110 \pm 45$ & 0.053 \\
\hline$t_{\mathrm{asc}}(\min )(\mathrm{n}=9)$ & $141 \pm 24$ & $139 \pm 23$ & $125 \pm 12$ & $128 \pm 18$ & 0.233 \\
\hline$t_{1 / 2}(\min )(\mathrm{n}=9)$ & $182 \pm 34$ & $177 \pm 25$ & $154 \pm 18$ & $179 \pm 61$ & 0.145 \\
\hline
\end{tabular}

$\mathrm{T}_{1 / 2}$, half time; $\mathrm{T}_{\text {lag, lag time; }} \mathrm{T}_{\mathrm{asc}}$, ascension time; $\mathrm{T}_{\text {lat }}$, latency time.

All values Mean $\pm S D(n=12)$.

a $\mathrm{n}=10$.

b Significantly different from caffeine, $p<0.05$. 


\section{Individual Energy Intake}

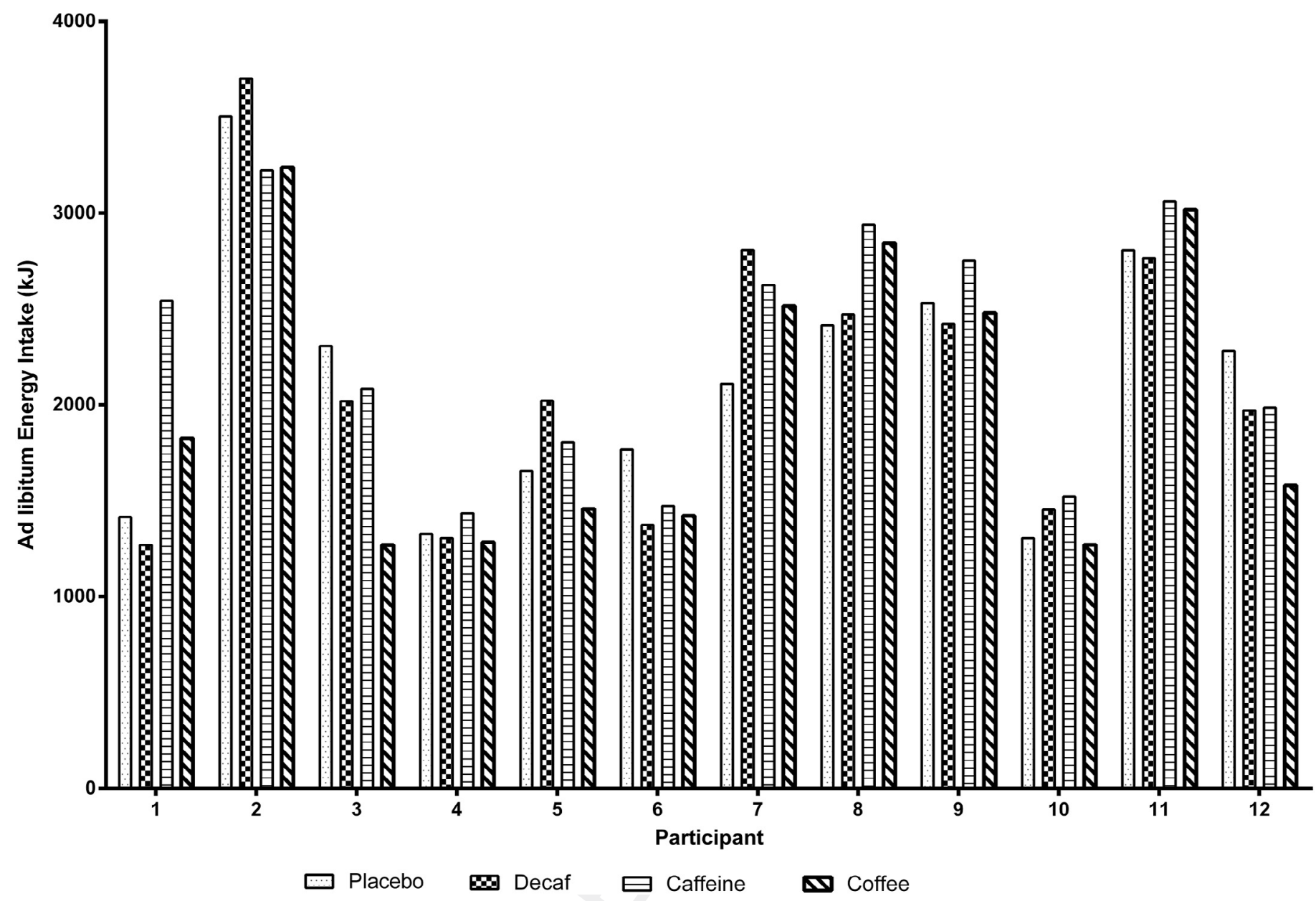

Fig. 2. Results for individual energy intake.

they remained for the rest of the trial period. In accordance with this, there were no differences between trials for glucose AUC $\left(F_{3,27}=0.649 ; p=0.594\right)$ (Table 3$)$.

\section{Correlates of energy intake}

Pearson correlation analysis unveiled several relationships between energy intake and other variables. BMI was inversely correlated with energy intake $(r=-0.549, p<0.001)$. Other correlates of energy intake included hunger AUC $(r=0.33, p=0.022)$, TFEQ Disinhibition score $(r=0.42, p=0.003)$, and TFEQ Hunger score $(r=0.438$, $p=0.002$ ).

\section{Discussion}

The objective of this study was to investigate the independent and combined effects of caffeine and coffee on acute ad libitum energy intake. The results indicated that caffeine or coffee did not alter energy intake, appetite perceptions, gastric emptying, or glucose when provided with a modest-sized breakfast compared to decaffeinated coffee or a placebo.

\section{Energy intake}

This study found no changes in energy intake with caffeine, decaffeinated, or caffeinated coffee consumption. This is in agreement with previous literature for caffeinated and decaffeinated coffee (Gavrieli et al., 2011, 2013), but not caffeine (Tremblay et al., 1988). It is possible that caffeine's ability to influence dopamine levels could in turn alter mood; and changes in mood can lead to alterations in energy intake (Macht, 2008; Macht \& Simons, 2000; Mela, 2006). Furthermore, the only study showing a significant effect of caffeine on energy intake found a suppression of energy intake only in men, not women, and the dose was administered $30 \mathrm{~min}$ before a meal when participants were fasted (Tremblay et al., 1988). Therefore, the temporal profile of the response could be important when examining the potential appetite-suppressing effect of caffeine. If the window is relatively short-lived ( $<60 \mathrm{~min})$, this could explain some of the differences in the results of Tremblay et al. (Tremblay et al., 1988) and the present and other recent studies (Gavrieli et al., 2011, 2013).

A paradox exists between acute and chronic studies on caffeine, coffee, and energy balance. The present and other acute studies examining the influence of coffee on energy intake generally have not observed decreases in energy consumption (Gavrieli et al., 2011, 2013). Additionally, two free-living studies that used split caffeine dosing similar to the present study (2x $\left.2.5 \mathrm{mg} \bullet \mathrm{kg}^{-1}\right)$ reported no changes in energy intake or body weight over four days of supplementation compared to a placebo period (Judice et al., 2013a,b). However, the epidemiological literature suggests coffee and caffeine consumption are associated with attenuated weight gain (Lopez-Garcia et al., 2006; Schubert et al., 2014). How can the 

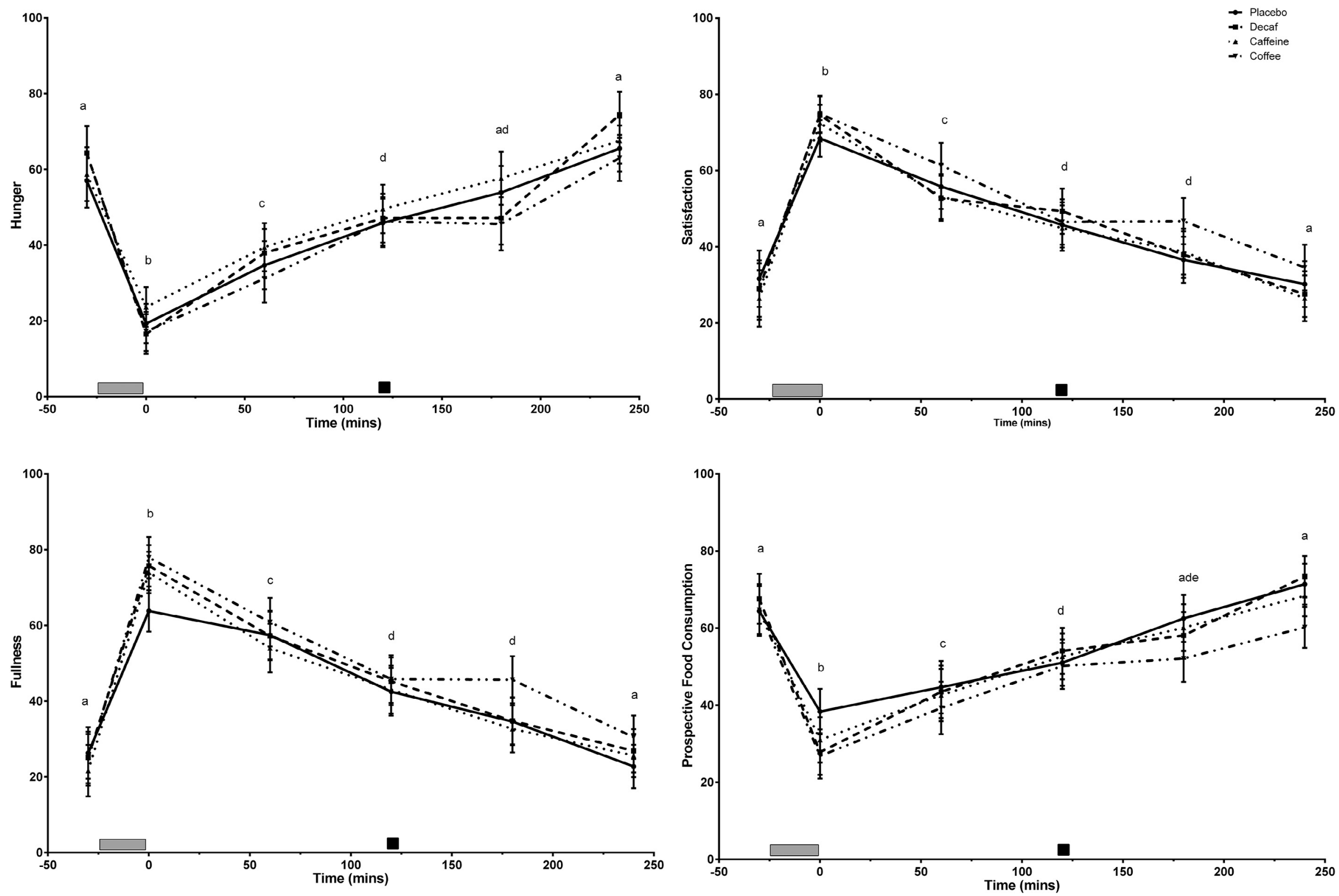

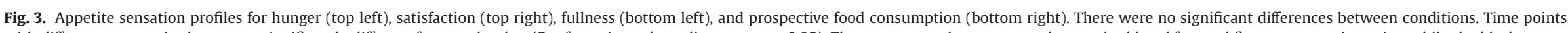

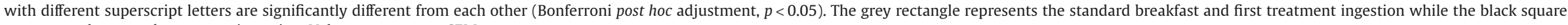
represents the second treatment ingestion. Values are means \pm SEM. 
discrepancy be explained? While it is clear caffeine has thermogenic effects (Hursel et al., 2011), the consumption of $5 \mathrm{mg} \cdot \mathrm{kg}^{-1}$ of caffeine per day over four days did not significantly change energy expenditure and voluntary activity as assessed by indirect calorimetry, accelerometry, or doubly-labelled water (Judice et al., 2013a,b). Long-term studies of caffeine supplementation for energy balance, independent of manipulations to diet, have not yet been conducted.

The influence of additives to coffee (milk, sugar, artificial sweetener) has not been well described in the literature. In the present study, participants had the option to add up to 1 teaspoon of artificial sweetener $(<16 \mathrm{~kJ})$ and two teaspoons of coffee whitener $(<20 \mathrm{~kJ})$, and the amount they chose to add was kept consistent between coffee conditions. Other studies (Gavrieli et al., 2011, 2013; Greenberg \& Geliebter, 2012) have not reported whether their participants were allowed to use additives with their coffee, which is interesting as it could be argued a significant portion of the population simply does not drink 'black' coffee (Bouchard, Ross, \& Janssen, 2010) and these factors may contribute to the subsequent food choices made by consumers. The influence of additives on energy intake both in single and multiple meals remains to be more thoroughly examined.

The finding of an inverse relationship between BMI and energy intake in the present study is curious and in disagreement with other research (Epstein, Lin, Carr, \& Fletcher, 2012). However, it is worth noting that while TFEQ Restraint score was not correlated with energy intake in the present study, it was moderately and significantly correlated with BMI (increased restraint correlated to increased BMI; data not shown). Thus, it is possible that the lack of differences in energy intake were influenced by participants' dietary restraint and this may be related to their perceptions of body composition (Davis, Durnin, Gurevich, Le Maire, \& Dionne, 1993) - even though there was no sign of an association between restraint and energy intake in the present study.

\section{Appetite sensations}

In agreement with prior research (Gavrieli et al., 2011, 2013), we found that caffeinated and decaffeinated coffee had minimal influences on appetite sensations. However, a separate study reported decreased hunger ratings after decaffeinated coffee consumption (Greenberg \& Geliebter, 2012). Some potential differences between study designs may explain some of the discrepancy, as this study used an oral glucose load and relatively large single bolus of coffee (500-600 mL) (Greenberg \& Geliebter, 2012). It is possible that gastric emptying rate may play a role in manipulating appetite perceptions, as we found that hunger, satisfaction, fullness, and prospective food consumption AUCs were all correlated with gastric emptying parameters. While caffeine and CGAs were not correlated with appetite perceptions, both have the ability to influence mood (Camfield et al., 2013; Smith, 2002), and it is possible a larger dose of these coffee constituents could have had an effect on mood, which in turn could have influenced appetite perceptions.

While our test meal was not designed to assess macronutrient intake, a prior study reported that caffeine suppressed energy intake in men (possibly mediated via a $50 \%$ decrease in fat consumption) (Tremblay et al., 1988). However, two recent studies found no evidence for altered macronutrient composition or preference at their test meal (Gavrieli et al., 2011, 2013). Another pair of studies, conducted in a free-living population, reported no differences in macronutrient intake over 4 days of caffeine supplementation, although in one of the studies, fat intake trended towards a reduction $(-13 \mathrm{~g} ; p=0.052)$ (Judice et al., 2013a,b). Whilst controlled studies allow for the exploration of caffeine and coffee's influence on appetite, future research should examine the influence of coffee and food selection at the point of purchase in a coffee shop-type setting as this is a more "real-world" setting where factors such as cost, availability, and social influence may more strongly drive eating behaviour (Collins, Freeman, \& Palmer, 2012; Freeman, Collins, \& Palmer, 2012).

\section{Gastric emptying}

This study found no significant differences in gastric emptying parameters when coffee or caffeine was co-ingested with a meal. This is agreement with some studies (Boekema, Lo, Samsom, Akkermans, \& Smout, 2000; Franke et al., 2008), but not others (Akimoto et al., 2009; Lien, Chen, Chang, Kao, \& Wang, 1995). Prior studies reporting unaltered gastric emptying utilised 16752500 kJ test meals (Boekema et al., 2000; Franke et al., 2008) while studies reporting accelerated gastric emptying have utilised 400800 kJ liquid boluses (Akimoto et al., 2009; Lien et al., 1995). Thus, it is probable that the energy content and form of the meal influences the impact of coffee on gastric emptying, with low-energy, liquid boluses emptying faster than higher-energy, solid meals. Our findings also illustrate that despite no mean differences, the SD was increased by about $50 \%$ during the coffee trial, illustrating greater variability in GE responses to coffee. Understanding the factors contributing to this variability and the implications for appetite and EI would be of interest for future study.

\section{Glucose}

Plasma glucose levels showed no influence of trial, which is in agreement with previous research (Gavrieli et al., 2011). When caffeine is co-ingested with carbohydrates (22-150 g), the effect of caffeine on immediate glucose responses appears to be minimal, although it may result in an exacerbated glycaemic and insulinaemic response at a later meal (Gavrieli et al., 2011; Hatonen et al., 2012; Moisey, Robinson, \& Graham, 2010). It has also been reported that CGAs may inhibit proximal glucose absorption causing a shift to more distal portions of the intestine, possibly mediated through altered incretin hormone release (Sim, Wallman, Fairchild, \& Guelfi, 2013). Additionally, carbohydrates may attenuate caffeine metabolism (Skinner et al., 2012), which may explain why studies that have administered caffeine when participants are fasted have yielded different results for energy intake than studies where participants consumed a meal with caffeine (Belza, Toubro, \& Astrup, 2009; Tremblay et al., 1988). The dose of CGAs in the current study is less than that reported to attenuate glucose absorption (Sim et al., 2013), while the dose of caffeine is also less than that commonly associated with disturbed glucose homeostasis (Beaudoin \& Graham, 2011). Thus, a moderate dose of coffee or caffeine, when consumed with a high carbohydrate meal, appears to exert little impact on glycaemic control.

\section{Strengths and limitations}

We designed this study to attempt to address appetitive responses to the ingestion of a 'typical' pattern of coffee consumption. The timing between the doses was selected to mimic typical consumption and also to consider the time-to-peak and half-life of caffeine. Caffeine levels typically peak $2-2.5 \mathrm{~h}$ after ingestion, though caffeine begins exerting effects within $0.75-1.5 \mathrm{~h}$ (Skinner et al., 2013a,b). Further, the half-life of caffeine is typically 4-6 h (Fredholm, Battig, Holmen, Nehlig, \& Zvartau, 1999). Though we did not measure caffeine levels after baseline, this design should have ensured that levels were still elevated by the time participants were offered their test meal, as we observed in a separate study with a similar design (Schubert et al., 2014). However, it is possible that caffeine concentration was not high enough to exert a noticeable effect due to the dose selected. 
The comprehensive nature and number of variables collected provided multiple avenues to examine the influence of caffeine and coffee on energy intake. This study, to our knowledge, is the first to simultaneously determine appetite, energy intake, and gastric emptying in response to separate and combined coffee and caffeine ingestion. The breakfast provided was similar in size and food items presented to what individuals might habitually consume, instead of the oral glucose load (Greenberg \& Geliebter, 2012) or white bread, butter, and sugar (Gavrieli et al., 2011, 2013) of prior studies. The use of two doses of caffeine/coffee providing levels similar to what participants habitually consumed can also be seen as a strength of the study, as it improves ecological validity. Furthermore, strict control of caffeine and energy intake leading up to the trials was implemented. A final strength of this study is that it was conducted primarily in women. A significant portion of the existing literature examining the influence of coffee and caffeine on appetite has been conducted in men (Belza et al., 2009; Gavrieli et al., 2011; Greenberg \& Geliebter, 2012).

This study also has several limitations. The first is that the small sample size may have limited the statistical power to detect significant differences. This is possibly compounded by the relatively high level of dietary restraint in our participants. While 12 is the accepted cut-off point for clinical restraint, recent research has suggested that 6 may be more appropriate (Aurelie et al., 2012). Thus, there is a possibility that the lack of differences in energy intake may be a consequence of the selected population exhibiting restraint at the test meal. The correlations between BMI and energy intake and BMI and restraint also suggest that the participants may have become aware that energy intake was being monitored during the course of the study. Furthermore, our sampling interval may not have been frequent enough to detect more subtle shifts in appetite perceptions or glucose over time. Another limitation is the nature of the blinding of participants, i.e. beverages versus capsules, so participants may have been able to delineate differences in treatments. However, post-trial feedback suggested this was likely not the case.

\section{Conclusions and implications}

The results of this study demonstrated that caffeine, decaffeinated coffee, and their combination had no significant influence on energy intake at a lunch meal and determinants of energy intake when the treatment was consumed with and $2 \mathrm{~h}$ after a moderately-sized breakfast. These results are in agreement with the findings of previous studies (Gavrieli et al., 2011, 2013). On a whole, data suggests that when coffee is taken with a meal, minimal effects on energy intake at a subsequent meal are observed; this also seems to hold true for caffeine. Future studies may wish to track energy intake over several subsequent meals while simultaneously measuring caffeine and caffeine/coffee metabolite concentrations (i.e. CGAs, paraxanthine) due to the half-lives of these compounds.

\section{Author contributions}

MS, ML, and BD conceived and designed the study. SS, GG, and NK contributed to the study design. MS recruited participants; performed the cannulations; prepared the meals; conducted the glucose analysis; collected, analysed, and interpreted the data. BD, SS, GG and ML assisted with data interpretation. MS and GG conducted the HPLC analyses. KH and MS calculated the GE results. MS wrote the initial version of the manuscript. All authors read and approved the final manuscript. The authors declare no conflict of interest, besides copious coffee consumption.

\section{References}

Akimoto, K., Inamori, M., Iida, H., Endo, H., Akiyama, T., Ikeda, T., et al. (2009). Does postprandial coffee intake enhance gastric emptying? A crossover study using continuous real time $13 \mathrm{C}$ breath test (BreathID system). Hepato-Gastroenterology, 56, 918-920.

Aurelie, L., Gilles, F., Jean-Jacques, D., Agathe, A., Sophie, V., Daniel, T., et al. (2012). Characterization of the Three-Factor Eating Questionnaire scores of a young French cohort. Appetite, 59, 385-390.

Beaudoin, M. S., \& Graham, T. E. (2011). Methylxanthines and human health. Epidemiological and experimental evidence. Handbook of Experimental Pharmacology, 509-548.

Belza, A., Toubro, S., \& Astrup, A. (2009). The effect of caffeine, green tea and tyrosine on thermogenesis and energy intake. European Journal of Clinical Nutrition, 63, 57-64.

Bergmann, J. F., Chassany, O., Petit, A., Triki, R., Caulin, C., \& Segrestaa, J. M. (1992). Correlation between echographic gastric emptying and appetite. Influence of psyllium. Gut, 33, 1042-1043.

Boekema, P. J., Lo, B., Samsom, M., Akkermans, L. M., \& Smout, A. J. (2000). The effect of coffee on gastric emptying and oro-caecal transit time. European Journal of Clinical Investigation, 30, 129-134.

Bouchard, D. R., Ross, R., \& Janssen, I. (2010). Coffee, tea and their additives. Association with BMI and waist circumference. Obesity Facts, 3, 345-352.

Bouchard, R., Weber, A. R., \& Geiger, J. D. (2002). Informed decision-making on sympathomimetic use in sport and health. Clinical Journal of Sport Medicine, 12, 209-224.

Camfield, D. A., Silber, B. Y., Scholey, A. B., Nolidin, K., Goh, A., \& Stough, C. (2013). A randomised placebo-controlled trial to differentiate the acute cognitive and mood effects of chlorogenic acid from decaffeinated coffee. PLOS ONE, 8, e82897.

Collins, A., Freeman, J., \& Palmer, M. (2012). Food and energy-dense beverage purchases at two major Australian cafes: purchasing behaviours and customer demographics. In Dietitians Association of Australia 16th International Congress of Dietetics (Vol. 69, p. 115). Sydney, Australia: Blackwell Publishing Asia.

Davis, C., Durnin, J. V., Gurevich, M., Le Maire, A., \& Dionne, M. (1993). Body composition correlates of weight dissatisfaction and dietary restraint in young women. Appetite, 20, 197-207.

Desbrow, B. (2011). Caffeine calculator (Vol. 2012).

Desbrow, B., Barrett, C. M., Minahan, C. L., Grant, G. D., \& Leveritt, M. D. (2009). Caffeine, cycling performance, and exogenous $\mathrm{CHO}$ oxidation. A dose-response study. Medicine and Science in Sports and Exercise, 41, 1744-1751.

Epstein, L. H., Lin, H., Carr, K. A., \& Fletcher, K. D. (2012). Food reinforcement and obesity. Psychological moderators. Appetite, 58, 157-162.

Flint, A., Moller, B. K., Raben, A., Sloth, B., Pedersen, D., Tetens, I., et al. (2006). Glycemic and insulinemic responses as determinants of appetite in humans. The American Journal of Clinical Nutrition, 84, 1365-1373.

Flint, A., Raben, A., Blundell, J. E., \& Astrup, A. (2000). Reproducibility, power and validity of visual analogue scales in assessment of appetite sensations in single test meal studies. International Journal of Obesity and Related Metabolic Disorders: Journal of the International Association for the Study of Obesity, 24, 38-48.

Franke, A., Harder, H., Orth, A. K., Zitzmann, S., \& Singer, M. V. (2008). Postprandial walking but not consumption of alcoholic digestifs or espresso accelerates gastric emptying in healthy volunteers. Journal of Gastrointestinal and Liver Diseases, 17, 27-31.

Fredholm, B. B., Battig, K., Holmen, J., Nehlig, A., \& Zvartau, E. E. (1999). Actions of caffeine in the brain with special reference to factors that contribute to its widespread use. Pharmacological Reviews, 51, 83-133.

Freeman, J., Collins, A., \& Palmer, M. (2012). Nutrient content, customer demographics, and purchase behaviours of purchases at two major cafe chains in Australia. In Dietitians Association of Australia 16th International Congress of Dietetics (Vol. 69 p. 39). Sydney, Australia: Blackwell Publishing Asia.

Gavrieli, A., Fragopoulou, E., Mantzoros, C. S., \& Yannakoulia, M. (2013). Gender and body mass index modify the effect of increasing amounts of caffeinated coffee on postprandial glucose and insulin concentrations; a randomized, controlled, clinical trial. Metabolism: Clinical and Experimental, 62, 1099-1106.

Gavrieli, A., Karfopoulou, E., Kardatou, E., Spyreli, E., Fragopoulou, E., Mantzoros, C. S., et al. (2013). Effect of different amounts of coffee on dietary intake and appetite of normal-weight and overweight/obese individuals. Obesity (Silver Spring, Md.), $0,1-6$.

Gavrieli, A., Yannakoulia, M., Fragopoulou, E., Margaritopoulos, D., Chamberland, J. P., Kaisari, P., et al. (2011). Caffeinated coffee does not acutely affect energy intake, appetite, or inflammation but prevents serum cortisol concentrations from falling in healthy men. The Journal of Nutrition, 141, 703-707.

Ghoos, Y. F., Maes, B. D., Geypens, B. J., Mys, G., Hiele, M. I., Rutgeerts, P. J., et al. (1993) Measurement of gastric emptying rate of solids by means of a carbon-labeled octanoic acid breath test. Gastroenterology, 104, 1640-1647.

Gibson, S., \& Shirreffs, S. M. (2013). Beverage consumption habits "24/7" among British adults. Association with total water intake and energy intake. Nutrition Journal, 12,9 .

Greenberg, J. A., \& Geliebter, A. (2012). Coffee, hunger, and peptide YY. Journal of the American College of Nutrition, 31, 160-166.

Gregersen, N. T., Flint, A., Bitz, C., Blundell, J. E., Raben, A., \& Astrup, A. (2008). Reproducibility and power of ad libitum energy intake assessed by repeated single meals. The American Journal of Clinical Nutrition, 87, 1277-1281. 
Harris, J. A., \& Benedict, F. G. (1918). A biometric study of human basal metabolism. Proceedings of the National Academy of Sciences of the United States of America, 4, 370-373.

Hatonen, K. A., Virtamo, J., Eriksson, J. G., Sinkko, H. K., Erlund, I., Jousilahti, P., et al. (2012). Coffee does not modify postprandial glycaemic and insulinaemic responses induced by carbohydrates. European Journal of Nutrition, 51, 801-806.

Hellmig, S., Von Schoning, F., Gadow, C., Katsoulis, S., Hedderich, J., Folsch, U. R., et al. (2006). Gastric emptying time of fluids and solids in healthy subjects determined by $13 \mathrm{C}$ breath tests. Influence of age, sex and body mass index. Journal of Gastroenterology and Hepatology, 21, 1832-1838.

Heyward, V. H. (2006). Advanced fitness assessment and exercise prescription (5th ed.). Champaign, IL, USA: Human Kinetics.

Hodgson, A. B., Randell, R. K., \& Jeukendrup, A. E. (2013). The metabolic and performance effects of caffeine compared to coffee during endurance exercise. PLOS ONE, 8, e59561.

Horner, K. M., Byrne, N. M., Cleghorn, G. J., \& King, N. A. (2013). Reproducibility of gastric emptying in overweight and obese males. Clinical Nutrition.

Hursel, R., Viechtbauer, W., Dulloo, A. G., Tremblay, A., Tappy, L., Rumpler, W., et al. (2011). The effects of catechin rich teas and caffeine on energy expenditure and fat oxidation. A meta-analysis. Obesity Reviews, 12, e573-e581.

Jackson, S. J., Bluck, L. J., \& Coward, W. A. (2004). Use of isotopically labelled octanoic acid to assess the effect of meal size on gastric emptying. Rapid Communications in Mass Spectrometry, 18, 1003-1007.

Judice, P. B., Magalhaes, J. P., Santos, D. A., Matias, C. N., Carita, A. I., Armada-Da-Silva, P. A., et al. (2013). A moderate dose of caffeine ingestion does not change energy expenditure but decreases sleep time in physically active males. A double-blind randomized controlled trial. Applied Physiology, Nutrition, and Metabolism, 38, 49-56.

Judice, P. B., Matias, C. N., Santos, D. A., Magalhaes, J. P., Hamilton, M. T., Sardinha, L. B., et al. (2013). Caffeine intake, short bouts of physical activity, and energy expenditure. A double-blind randomized crossover trial. PLoS ONE, 8, e68936.

Lien, H. C., Chen, G. H., Chang, C. S., Kao, C. H., \& Wang, S. J. (1995). The effect of coffee on gastric emptying. Nuclear Medicine Communications, 16, 923-926.

Lopez-Garcia, E., van Dam, R. M., Rajpathak, S., Willett, W. C., Manson, J. E., \& Hu, F. B. (2006). Changes in caffeine intake and long-term weight change in men and women. The American Journal of Clinical Nutrition, 83, 674-680.

Macht, M. (2008). How emotions affect eating. A five-way model. Appetite, 50, 1-11.

Macht, M., \& Simons, G. (2000). Emotions and eating in everyday life. Appetite, 35, 65-71.

McArthur, K. E., \& Feldman, M. (1989). Gastric acid secretion, gastrin release, and gastric emptying in humans as affected by liquid meal temperature. The American Journal of Clinical Nutrition, 49, 51-54.

McNeil, J., \& Doucet, E. (2012). Possible factors for altered energy balance across the menstrual cycle. A closer look at the severity of PMS, reward driven behaviors and leptin variations. European Journal of Obstetrics, Gynecology, and Reproductive Biology, 163, 5-10.
Mela, D. J. (2006). Eating for pleasure or just wanting to eat? Reconsidering sensory hedonic responses as a driver of obesity. Appetite, 47, 10-17.

Moisey, L. L., Robinson, L. E., \& Graham, T. E. (2010). Consumption of caffeinated coffee and a high carbohydrate meal affects postprandial metabolism of a subsequent oral glucose tolerance test in young, healthy males. The British Journal of Nutrition, $103,833-841$

Narita, Y., \& Inouye, K. (2013). Degradation kinetics of chlorogenic acid at various $\mathrm{pH}$ values and effects of ascorbic acid and epigallocatechin gallate on its stability under alkaline conditions. Journal of Agricultural and Food Chemistry, 61, 966-972.

Schommartz, B., Ziegler, D., \& Schadewaldt, P. (1998). Significance of diagnostic parameters in $[13 \mathrm{C}$ loctanoic acid gastric emptying breath tests. Isotopes in Environmental and Health Studies, 34, 135-143.

Schubert, M. M., Hall, S., Leveritt, M., Grant, G., Sabapathy, S., \& Desbrow, B. (2014) Caffeine consumption around an exercise bout. Effects on energy expenditure, energy intake, and exercise enjoyment. Journal of Applied Physiology (1985), pii: jap.00570.2014

Sim, A. Y., Wallman, K. E., Fairchild, T. J., \& Guelfi, K. J. (2013). High-intensity intermittent exercise attenuates ad-libitum energy intake. International Journa of Obesity (2005), 38, 417-422.

Skinner, T. L., Jenkins, D. G., Folling, J., Leveritt, M. D., Coombes, J. S., \& Taaffe, D. R. (2012). Influence of carbohydrate on serum caffeine concentrations following caffeine ingestion. Journal of Science and Medicine in Sport, doi:10.1016 j.jsams.2012.08.004.

Skinner, T. L., Jenkins, D. G., Leveritt, M. D., McGorm, A., Bolam, K. A., Coombes, J. S. et al. (2013a). Factors influencing serum caffeine concentrations following caffeine ingestion. Journal of Science and Medicine in Sport.

Skinner, T. L., Jenkins, D. G., Taaffe, D. R., Leveritt, M. D., \& Coombes, J. S. (2013b). Coinciding exercise with peak serum caffeine does not improve cycling performance. Journal of Science and Medicine in Sport, 16, 54-59.

Smith, A. (2002). Effects of caffeine on human behavior. Food and Chemical Toxicology: An International Journal Published for the British Industrial Biological Research Association, 40, 1243-1255.

Stunkard, A. J., \& Messick, S. (1985). The three-factor eating questionnaire to measure dietary restraint, disinhibition and hunger. Journal of Psychosomatic Research, 29 71-83.

Tremblay, A., Masson, E., Leduc, S., Houde, A., \& Despres, J. P. (1988). Caffeine reduces spontaneous energy intake in men but not women. Nutrition Research (New York N.Y.), 8, 554-558.

Turnbull, W. H., \& Thomas, H. G. (1995). The effect of a Plantago ovata seed containing preparation on appetite variables, nutrient and energy intake. International Journa of Obesity and Related Metabolic Disorders: Journal of the International Association for the Study of Obesity, 19, 338-342.

Westerterp, K. R., Donkers, J. H., Fredrix, E. W., \& Boekhoudt, P. (1995). Energy intake, physical activity and body weight. A simulation model. The British Journal of Nutrition, 73, 337-347. 